\title{
Perbandingan Desain Ipal Anaerobic Biofilter dengan Rotating Biological Contactor untuk Limbah Cair Tekstil di Surabaya
}

\author{
Yogie Restu Firmansyah, dan Dr. Ir. Mohammad Razif, M.M. \\ Jurusan Teknik Lingkungan, Fakultas Teknik Sipil dan Perencanaan, Institut Teknologi Sepuluh \\ Nopember (ITS) \\ Jl. Arief Rahman Hakim, Surabaya 60111 Indonesia \\ e-mail: Yogie.restu12@mhs.enviro.its.ac.id, Razif@enviro.its.ac.id
}

\begin{abstract}
Abstrak - Effluen Instalasi Pengolahan Air Limbah (IPAL) di Pabrik Tekstil $X$ belum memenuhi kriteria yang ada, terutama untuk masalah warna. Sistem pengolahan IPAL menggunakan Anaerobic Biofilter memiliki kelebihan menyisihkan bahan organik yang tinggi, kebutuhan lahan yang relatif tidak besar, dan biaya operasi yang murah dibandingkan dengan sistem lumpur aktif yang menggunakan proses aerasi. Rotating Biological Contactor (RBC) juga memiliki kelebihan yang sama dengan anaerobic biofilter. Perbandingan antara kedua sistem tersebut diperlukan untuk mengetahui sistem yang paling efektif untuk mengolah air limbah di Pabrik Textil X. Pengolahan adsorbsi batok arang kelapa dipilih untuk menghilangkan warna. Perencanaan ini dilakukan dengan menggunakan metode yang sistematis dimulai pengumpulan data primer dan sekunder yang berupa data karakteristik dan debit air limbah, lalu dilakukan perhitungan dan penggambaran Detail Engineering Desan (DED), volume pekerjaan dan Rancangan Anggaran Biaya (RAB), setelah itu dilakukan pembahasan untuk membandingkan kelebihan dan kekurangan dari unit anaerobic Biofilter yang dilengkapi adsorbsi arang batok kelapa dan Rotating Biological Contactor yang dilengkapi adsorbsi arang batok kelapa, lalu diambil kesimpulan dan saran yang relevan dengan tujuan dari perancanaan ini. Dari perhitungan DED didapat dimensi untuk masing masing unit IPAL sebagai berikut Bak ekualisasi $(2,6 \mathrm{~m} \times$ 2,6 m x 2 m), Septic tank (1,75 m x 1,5m x 2,5m), Anaerobic Filter 4 kompartemen $(4,5 \mathrm{~m} \times 2,5 \mathrm{~m} \times 2,5 \mathrm{~m})$, RBC 2 shaft $(2,75 \mathrm{~m} \times$ $2,75 \mathrm{~m} \times 1 \mathrm{~m})$, Adsorbsi (3,5 mx 6,75m x 0,55m). Biaya investasi alternative 1 sebesar $R p \quad 700.193 .694,29$, biaya operasi sebesar Rp 50.222.462,40, biaya perawatan sebesar Rp 3.495.000,00. Alternatif 2 biaya investasi sebesar $R p$ 777.526.655,53, biaya operasi sebesar Rp Rp 53.012.599,20 , biaya perawatan sebesar Rp 3.495.000,00. Kelebihan anaerobic filter adalah biaya investasi yang lebih kecil, kebutuhan lahan yang lebih sedikit yaitu $45 \mathrm{~m} 2$, biaya operasional dan perawatan yang lebih kecil, jumlah lumpur yang dihasilkan lebih sedikit., sedangkan kekurangannya adalah waktu tinggal yang lebih lama dan start up yang lama. Kelebihan RBC adalah waktu tinggal yang lebih singkat yaitu 1,5 jam, waktu start-up yang lebih singkat, , sedangkan kekurangannya memerlukan energi listrik dan biaya investasi dan operasional yang lebih tinggi.
\end{abstract}

Kata Kunci-Anaerobic Filter, Desain, Rotating Biological Contactor, Tekstil.

\section{PENDAHULUAN}

$\mathrm{P}$ ABRIK Tekstil X, sebagai salah satu pabrik tekstil yang terdapat di Surabaya berupaya untuk mengelola limbah yang dihasilkannya dengan melakukan pengolahan terhadap limbah cair yang dikeluarkan ke dalam suatu Instalasi Pengolahan Air Limbah (IPAL). Rata-rata penggunaan air untuk industri tekstil adalah pada proses penggelantangan 200$300 \mathrm{~m}^{3}$ dan pada proses pencelupan 30-60 $\mathrm{m}^{3}$ [1]. Upaya untuk mengolah air limbah diharapkan dapat mengurangi beban pencemaran terhadap lingkungan sehingga memenuhi baku mutu air limbah industri. Effluen IPAL yang ada di Pabrik Tekstil $\mathrm{X}$ masih belum memenuhi kriteria yang ada, terutama untuk masalah warna. Selain effluent yang masih berwarna umur IPAL yang ada di Pabrik Tekstil X telah berumur lebih dari 30 tahun. Hal tersebut dapat mempengaruhi efisiensi pengolahan IPAL sehingga effluent yang dihasilkan semakin menurun.

Sistem pengolahan IPAL menggunakan Anaerobic Biofilter memiliki kelebihan menyisihkan bahan organik yang tinggi, kebutuhan lahan yang relatif tidak besar, dan biaya operasi yang murah dibandingkan dengan sistem lumpur aktif atau tangki aerasi karena menggunakan proses aerasi [2]. Aerobic Rotating Biological Contactor juga memiliki kelebihan yang sama dengan anaerobic biofilter maka diperlukan perencanaan lebih lanjut untuk membandingkan kedua pengolahan ini. Pengolahan dengan aerobic pada limbah tekstil dapat menghlangkan kadar COD 39-51\% sebesar dan kadar warna sebesar 20-42\% [3].

Pengolahan lanjutan berupa adsorbsi arang batok kelapa dibutuhkan untuk menurunkan kadar warna. Penurunan kadar warna pada limbah cair batik oleh adsorben arang batok kelapa mencapai $77 \%-100 \%$ [4].

Perencanaan ini akan membandingkan antara kelebihan dan kekurangan untuk desain IPAL anaerobic Biofilter yang dilengkapi adsorbsi arang batok kelapa dan Aerobic Rotating Biological Contactor yang dilengkapi adsorbsi arang batok kelapa. Parameter pembanding untuk kelebihan dan kekurangan IPAL yang digunakan meliputi beban pekerjaaan, efisiensii penyisihan, luas lahan, volume dan rencana anggaran biaya. Parameter pembanding akan membantu dalam menentukan desain IPAL yang paling efisien dalam hal aspek dan finansial untuk limbah industri tekstil. 


\section{METODE PERENCANAAN}

\section{A. Alternatif pengolahan yang direncanakan}

Perencanaan ini membandingkan dua alternatif unit IPAL yang akan dibandingkan kelebihan dan kekurangannya meliputi efisiensi penyisihan, luas lahan, volume dan rencana anggaran biaya. Alternatif unit IPAL sebagai berikut: Unit IPAL yang digunakan meliputi unit bak ekualisasi Anaerobic BioFilter dengan dilengkapi adsorbsi arang batok kelapa dan Aerobic Rotating Biological Contactor dengan dilengkapi adsorbsi arang batok kelapa.

Alternatif IPAL 1:

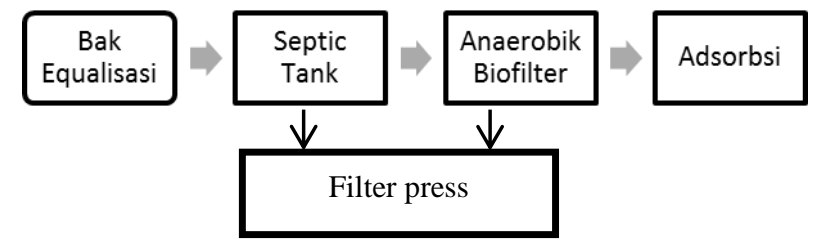

Gambar 1. Skema Perencanaan IPAL Alternatif 1 Alternatif IPAL 2:

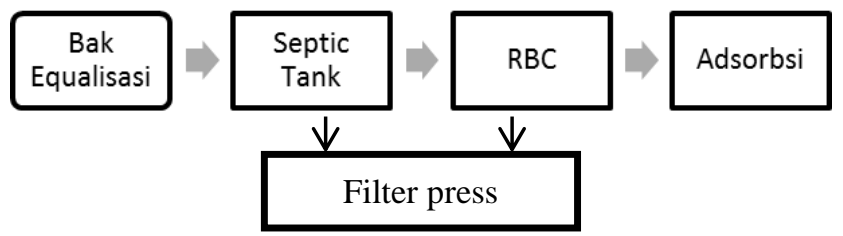

Gambar 2. Skema Perencanaan IPAL Alternatif 2

\section{B. Kerangka perencanaan}

Data yang dibutuhkan untuk melakukan perencanaan dan perbandingan desain alternatif 1 dan 2 meliputi debit air limbah diperoleh dari kapasitas mesin produksi, karakteristik air limbah tekstil diperoleh dari data primer hasil analisis laboratorium. Analisis dilaksanakan di Laboratorium Teknik Lingkungan ITS, Surabaya. Perhitungan rencana anggaran biaya menggunakan HSPK Kota Surabaya tahun 2015. Baku mutu air limbah industri yang digunakan adalah Peraturan Gubernur Jawa Timur no 72 tahun 2013 tentang Baku Mutu Air Limbah Bagi Industri dan Kegiatan/Usaha lainnya.

Pengolahan data adalah deskriptif perencanaan yang dijelaskan secara mendalam dan ilmiah. Perencanaan ini membandingkan 2 alternatif perencanaan untuk mengolah air limbah tekstil Pabrik X. Pengolahan data yang dilakukan meliputi, perhitungan debit air limbah, penetapan baku mutu air limbah dan penetapan kriteria desain yang sesuai dengan pustaka. Perhitungan sesuai kriteria desain dan rumus yang diperlukan untuk mendapat dimensi dari masing-masing unit di dalam alternatif desain. Penggambaran DED (Detail Enggineering Design) bagunan dilakukan sesuai kaidah gambar teknik. Hasil dari perhitungan desain dan gambar DED digunakan untuk menghitung beban pekerjaan masing-masing unti IPAL yang selanjutnya akan digunakan untuk menghitung RAB (Rancangan Anggaran Biaya). Rancangan anggaran biaya investasi dan operasi selama 5 tahun dibandingkan untuk mengetahui alternatif IPAL yang lebih baik.

\section{HASIL DAN PEMBAHASAN}

\section{A. Debit dan Karakteristik Air Limbah}

Mesin pencelupan di pabrik tekstil x menghasilkan limbah cair sebesar 81.000 L/hari setara dengan $81 \mathrm{~m}^{3} /$ hari. Perencanaan ini digunakan debit yang diolah di ipal sebesar 81 $\mathrm{m}^{3} /$ hari. Karakteristik air limbah dapat dilihat di tabel 1 .

Tabel 1. Karakteristik Air Limbah

\begin{tabular}{ccc}
\hline \hline Parameter & Nilai & Satuan \\
\hline BOD & 1640 & $\mathrm{mg} / \mathrm{L}$ \\
COD & 2645 & $\mathrm{mg} / \mathrm{L}$ \\
TSS & 364 & $\mathrm{mg} / \mathrm{L}$ \\
PH & 10,6 & \\
Warna & 130 & Pt.co \\
\hline \hline
\end{tabular}

Hasil uji laboratorium tersebut menunjukkan bahwa rasio BOD/COD sebesar 0,62. Rasio BOD/COD yang lebih dari 0,5 dijadikan tolak ukur bahwa limbah tersebut dapat diolah dengan menggunakan proses biologis [5].

\section{B. Bak ekualisasi}

Bak ekualisasi yang direncanakan menggunakan pompa untuk mengalirkan air limbah yang akan diolah. Aliran diharapkan dapat mengalir secara konstan dan terjadi sirkulasi di dalam bak ekualisasi sehingga tidak terbentuk endapan. Pompa yang direncanakan adalah pompa submersible. Rumus yang digunakan untuk perhitungan bak ekualisasi sebagai berikut.

volume bak $=(\mathrm{HRT} / 24) \times \mathrm{Q}$

$\mathrm{As}=\mathrm{Vbak} / \mathrm{h}$

$\mathrm{p}=\mathrm{As} \mathrm{s}^{0,5}$

$1=\mathrm{As}^{0,5}$

Rumus 1 sampai 4 menghasilkan dimensi bak ekualisasi yaitu panjang 2,6 m, lebar 2,6 $\mathrm{m}$ dan kedalaman $2 \mathrm{~m}$. Pompa yang digunakan adalah tipe SL1.30.A40.20.4.60J.C Gambar denah dan potongan unit bak ekualisasi dapat dilihat pada gambar 3.

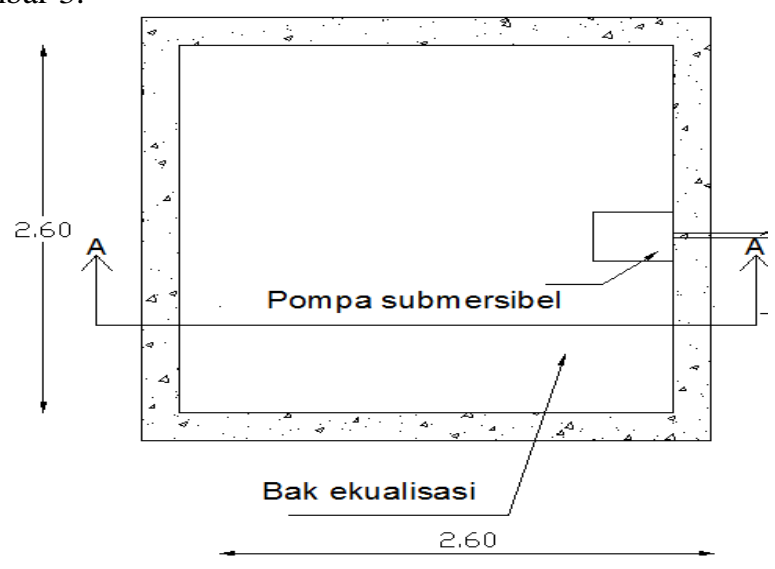

Tampak atas

(a) 


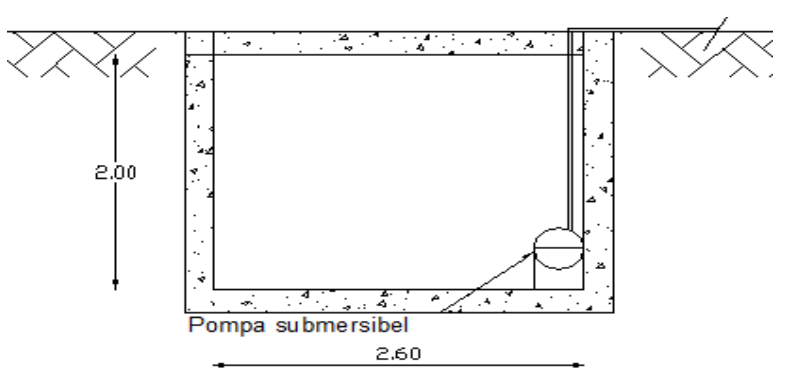

(b)

Gambar 3. Gambar (a) Denah Unit Bak Ekualisasi, (b) Potongan A-A Bak Ekualisasi.

\section{Septic tank}

Lokasi peletakan septic tank yang setelah bak ekualisasi. Hal ini dimaksudkan septic tank bertindak sebagai pengolahan awal sebelum limbah diolah secara biologis di anaerobic filter atau rotating biological contactor. Septic tank yang direncanakan berfungsi untuk mengendapkan partikel suspended solid yang ada di dalam limbah. Tinggi muka air yang direncanakan adalah 2,5 $\mathrm{m}$ sehingga dapat terjadi proses penyisihan suspended solid yang maksimal. Septic tank yang direncanakan memiliki 2 ruang. Septic tank disekat dengan baffle, sehingga scum yang ada di ruang pertama tidak dapat masuk ke sistem pengolahan selanjutnya. Rumus yang digunakan untuk menghitung efisensi pengolahan dan dimensi septic tank sebagai berikut.

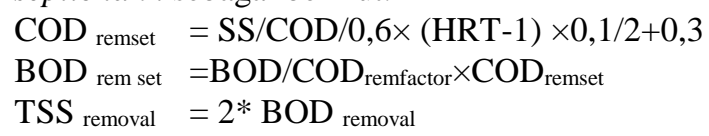

$\mathrm{TSS}_{\text {removal }}=2 * \mathrm{BOD}_{\text {removal }}$

Keterangan:

Q = Debit air limbah $\left(\mathrm{m}^{3} /\right.$ hari $)$

HRT = Waktu tinggal air limbah (hari)

Persamaan 5 mengghasilkan $31 \%$ penyisihan COD. COD removal settling lebih dari $30 \%$ maka $\mathrm{BOD} / \mathrm{COD}$ remfactor adalah 1,06 [6]. $\mathrm{BOD}_{\text {remset }}$ dan $\mathrm{TSS}_{\text {removal }}$ yang didapat sebesar $33 \%$ dan $66 \%$.

Akumulasi lumpur $=0,005 \times(1$ - (interval pengurasan $\times$ $0,014)$

Bak pengendap $=$ akumulasi lumpur $\times\left(\mathrm{BOD}_{\text {in }}-\mathrm{BOD}_{\text {out }}\right) /$ $1000 \times$ pengurasan $\times 30 \times \mathrm{Q}+\mathrm{HRT}_{\text {sett }} \times \mathrm{Q}_{\text {perj }}$ am

Panjang bak pertama $=2 / 3 \times$ volume bak pengendap/lebar dalam $/ H$.minimum air pada inlet

Panjang bak ke dua $=0,5 \times$ panjang bak pertama (11)

Perhitungan 8 sampai 9 menghasilkan dimensi septic tank panjang $1,5 \mathrm{~m}$, lebar $1,75 \mathrm{~m}$ dan kedalaman $2,5 \mathrm{~m}$. Gambar denah dan potongan unit septic tank dapat dilihat pada gambar 4.

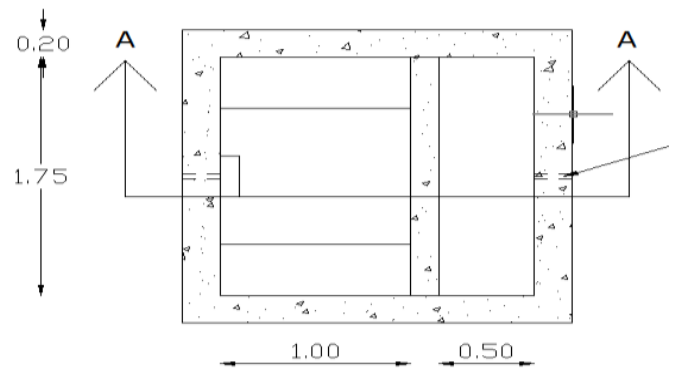

(a)

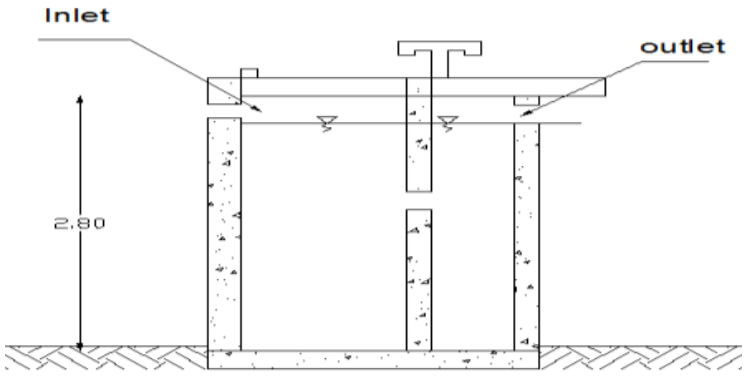

(b)

Gambar 4. Gambar (a) Denah Unit Septic tank , (b) Potongan A-A Septic Tank.

\section{Anaerobic filter}

Anaerobic filter yang drencanakan memiliki jumlah 4 kompartemen dan dipasang secara seri. Media filter yang dipilih adalah media sarang tawon. Media sarang tawon dipilih karena memiliki poros media yang mencapai $98 \%$ [7]. Rumus yang digunakan untuk menghitung efisensi pengolahan dan dimensi anaerobic filter sebagai berikut [6].

Factor temperature $=($ temperatur limbah-25) $\times 0,08 / 5+1$

Factor konsentrasi $=\left(\mathrm{COD}_{\text {in AF }}-2000\right) \times 0,02 / 1000+1,04$

Faktor luas area $\quad=\left(\mathrm{A}_{\text {spesifik filter }}-100\right) \times 0,06 / 100+1$

Faktor HRT $\quad=($ HRT AF-24)*0,03/ 9+0,67

CODremaf

$=\mathrm{f}_{\text {temp }} \times \mathrm{F}_{\text {strength }} \times \mathrm{F}_{\text {surfac }} \times \mathrm{F}_{\text {HRT }} \times(1+$ (jumlah kompartemen* 0,04$)$

COD eff

V tangki filter

$=\mathrm{COD}$ inf anaerobic filter $\times\left(1-\mathrm{COD}_{\text {rem af }}\right)$

Lebar kamar

$=\mathrm{HRT} \times \mathrm{Q}$

$=\mathrm{v}_{\text {tangki filter }} / \mathrm{jumlah}$ kompartemen/

(kedalaman $\times 0,25)+($ panjang kompartemenketinggian media filter $\times$ (1-porositas media)

Rumus 12 sampai 17 menghasilkan dimensi anaerobic filter panjang $1,5 \mathrm{~m}$, lebar $1,75 \mathrm{~m}$ dan kedalaman 2,5 m. Gambar denah dan potongan unit septic tank dapat dilihat pada gambar 5.

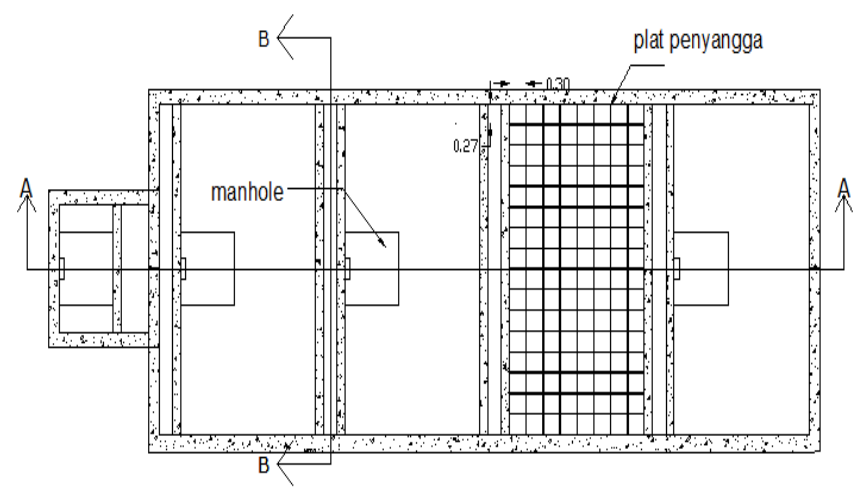

(a)

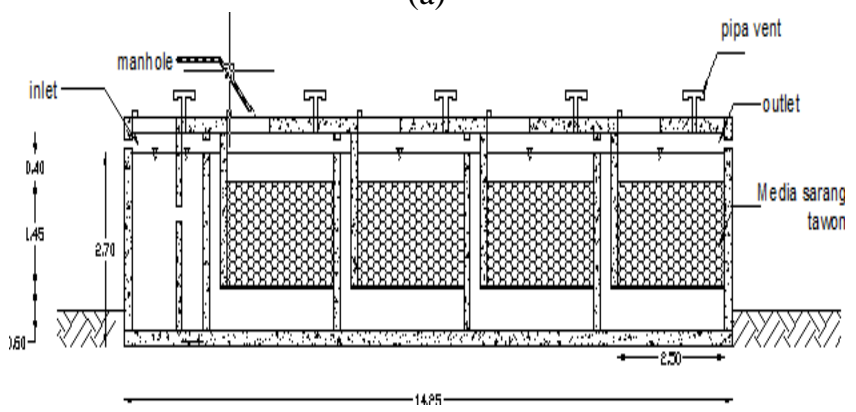

(b) 


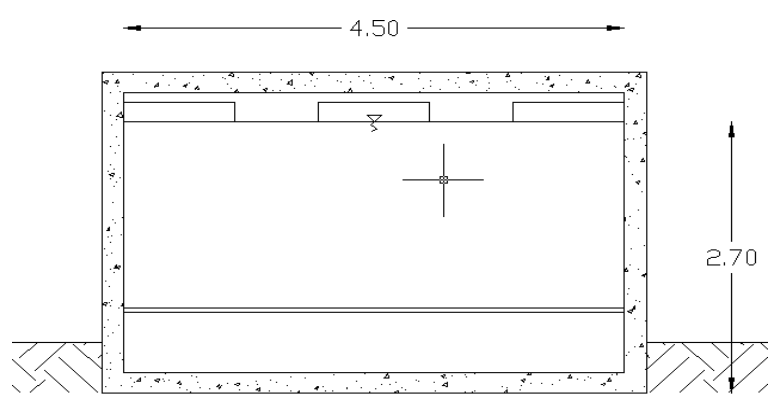

(c)

Gambar 5. Gambar (a) Denah Unit Anaerobic Filter, (b) Potongan A-A Anaerobic Filter, (c) Potongan B-B Anaerobic Filter.

\section{E. Rotating Biological Contactor}

Rumus yang digunakan untuk menghitung efisensi pengolahan dan dimensi Rotating Biological Contactor sebagai berikut [5].

BOD loading $=$ konsentrasi BOD masuk $\times \mathrm{Q}$

As cakram $=B O D_{\text {loading }}$ /organic loading di tahap pertama

Jumlah shaft $/$ train $=$ As cakram $/$ As $_{\text {standart }}$

Kebutuhan plate $=$ As cakram $/ \mathrm{As}_{\text {plate }} \times 2$

Volume bak $=\mathrm{Q} / 24 \times \mathrm{HRT}$

Panjang bak $\quad=$ panjang shaft $/ 3$

$=40 \%$ dari diameter rbc

Rumus 18 sampai 24 menghasilkan dimensi Rotating Biological Contactor panjang 2,7 m, lebar 2,7 m dan kedalaman $1 \mathrm{~m}$. Gambar denah dan potongan unit Rotating Biological Contactor dapat dilihat pada gambar 6.

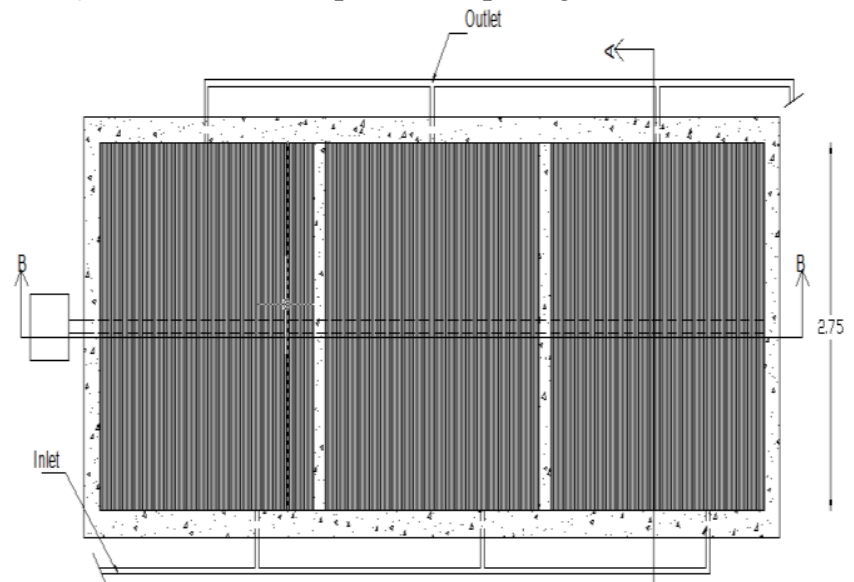

(a)

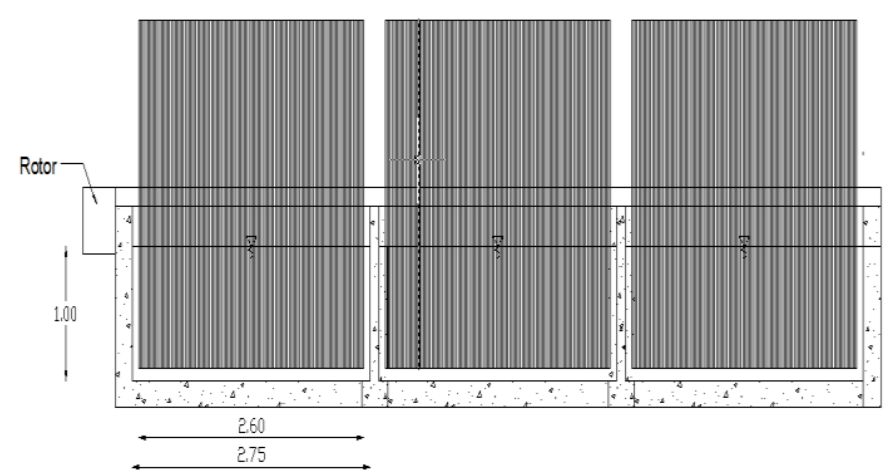

(b)

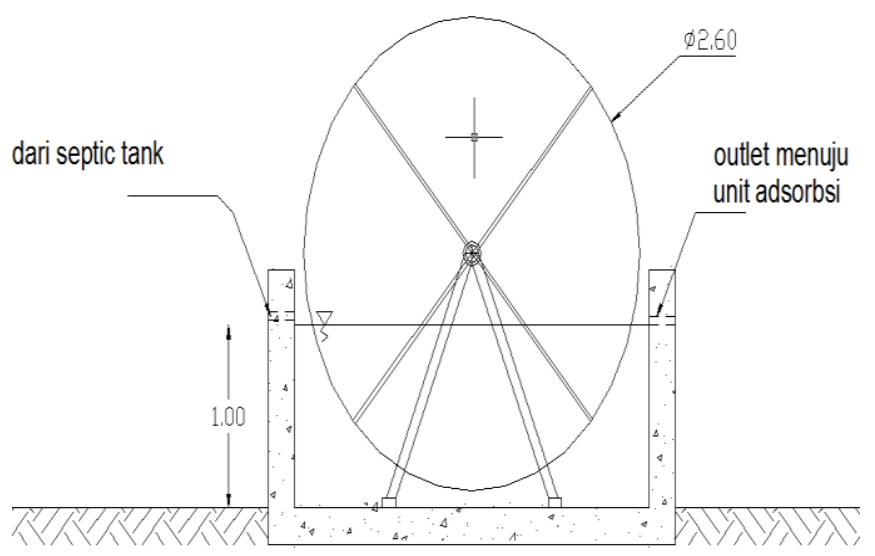

(c)

Gambar 6. Gambar (a) Denah Unit RBC, (b) Potongan A-A RBC, (c) Potongan B-B RBC.

\section{F. Adsorbsi arang batok kelapa}

Unit adsorbsi akan diletakkan setelah unit pengolahan sekunder dari masing-masing alternatif. Arah aliran dari adasorbsi ini adalah horizontal, arah aliran ini dipilih karena tidak memerlukan pompa untuk mengalirkan air limbah sehingga biaya operasi dapat diminimalkan. Reaktor yang digunakan berupa pipa pvc dengan panjang 3 meter, hal ini dipilih karena pipa pvc yang ada dipasaran berkisar 6 meter yang dikira terlalu panjang maka panjang pipa dibagi 2 menjadi 3 meter. Rumus yang digunakan untuk menghitung dimensi adsorbsi arang batok kelapa sebagai berikut [8].

$\mathrm{M}=\mathrm{Q} / \mathrm{vb} /$ massa karbon

$\mathrm{Mt}=$ volume treated per $\mathrm{kg}$ arang/Qperjam

$\mathrm{Tb}=\mathrm{M} / \mathrm{Mt}$

Volume $_{\text {yang dibutuhkan }}=\mathrm{M} / \rho \mathrm{s}$

$\mathrm{V}_{\text {satu reaktor }}=0,25 \times 3,14 \times \mathrm{D}^{2} \times$ panjang reactor

Kebutuhan reaktor $=$ Volume yang dibutuhkan $/ \mathrm{V}_{\text {satu reactor }}$

Keterangan:

$\mathrm{ps}=$ Berat jenis arang batok kelapa

$\mathrm{M}=$ Massa arang

$\mathrm{Mt}=$ Massa adsorbent yang habis per jam

$\mathrm{Tb}=$ breaktrough time

Rumus 25 sampai 30 menghasilkan dimensi panjang $3 \mathrm{~m}$, diameter $0,27 \mathrm{~m}$ dan jumlah reaktor 48 buah. Gambar unit adsorbsi arang batok kelapa dapat dilihat pada gambar 7 .

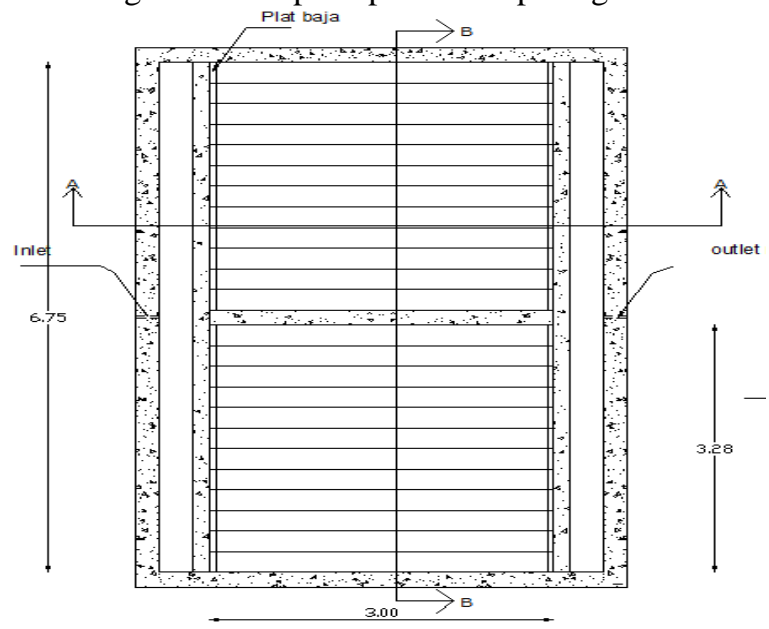

(a) 


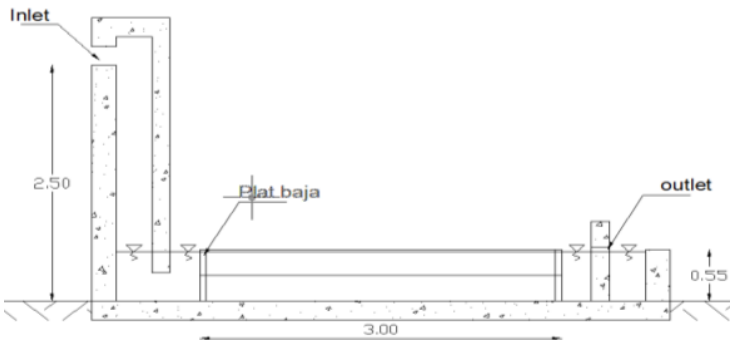

(b)

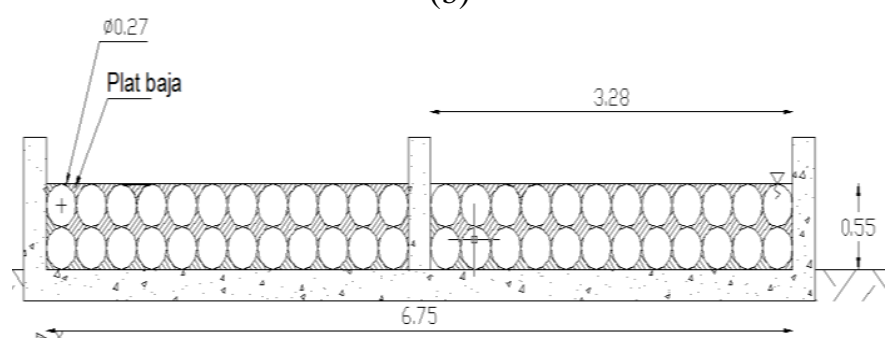

(c)

Gambar 7. Gambar (a) Denah Unit Adsorbsi, (b) Potongan A-A Adsorbsi, (c) Potongan B-B Adsorbsi.

\section{G. Filter Press}

Filter press melakukan proses dewatering dengan cara memberi tekanan yang tinggi pada 2 plate yang berbentuk segiempat [5]. Filter press yang direncanakan akan mengolah lumpur yang dihasilkan dari septic tank dan pengolahan biologis. Alternatif 1 menghasilkan lumpur sebesar 0,0003 $\mathrm{m}^{3} /$ hari dan alternatif 2 menghasilkan lumpur sebesar $0,9108 \mathrm{~m}^{3} /$ hari. Rumus yang digunakan untuk menghitung kebutuhan filter press sebagai berikut.
Volume Filter press $=$ volume lumpur yang dihasilkan $\times \%$ solids $\times$ specific gravity lumpur/densitas dari filter cake $(\mathrm{kg} / \mathrm{L}) \times \%$ dry solids filter cake

Kapasitas Filter press yang dibutuhkan untuk Alternatif 1 adalah 14,8 L dan alternatif 2 sebesar48 L. Peletakan filter press dapat dilihat di layout alternatif 1 dan 2 gambar 8 .

Perhitungan RAB dilakukan dengan menghitung beban pekerjaan dikalikan faktor indeks yang ada di HSPK. Hasil RAB dapat dilihat pada tabel 3 .

Tabel 3. RAB Alternatif 1 dan Alternatif 2

\begin{tabular}{lcr} 
& Alternatif 1 \\
Unit & $\mathrm{RAB}$ & \\
Bak ekualisasi & $\mathrm{Rp}$ & $71.179 .529,95$ \\
septic tank & $\mathrm{Rp}$ & $39.155 .079,60$ \\
Anaerobic filter & $\mathrm{Rp}$ & $350.401 .060,85$ \\
adsorbsi & $\mathrm{Rp}$ & $125.363 .496,12$ \\
Pengolahan lumpur & $\mathrm{Rp}$ & $114.094 .527,77$ \\
Total & $\mathrm{Rp}$ & $700.193 .694,29$ \\
& Alternatif 2 \\
Unit & $\mathrm{RAB}$ \\
Bak ekualisasi & $\mathrm{Rp}$ & $71.179 .529,95$ \\
septic tank & $\mathrm{Rp}$ & $39.155 .079,60$ \\
RBC & $\mathrm{Rp}$ & $423.762 .653,90$ \\
adsorbsi & $\mathrm{Rp}$ & $125.363 .496,12$ \\
Pengolahan lumpur & $\mathrm{Rp}$ & $118.065 .895,97$ \\
Total & $\mathrm{Rp}$ & $777.526 .655,53$ \\
\hline
\end{tabular}
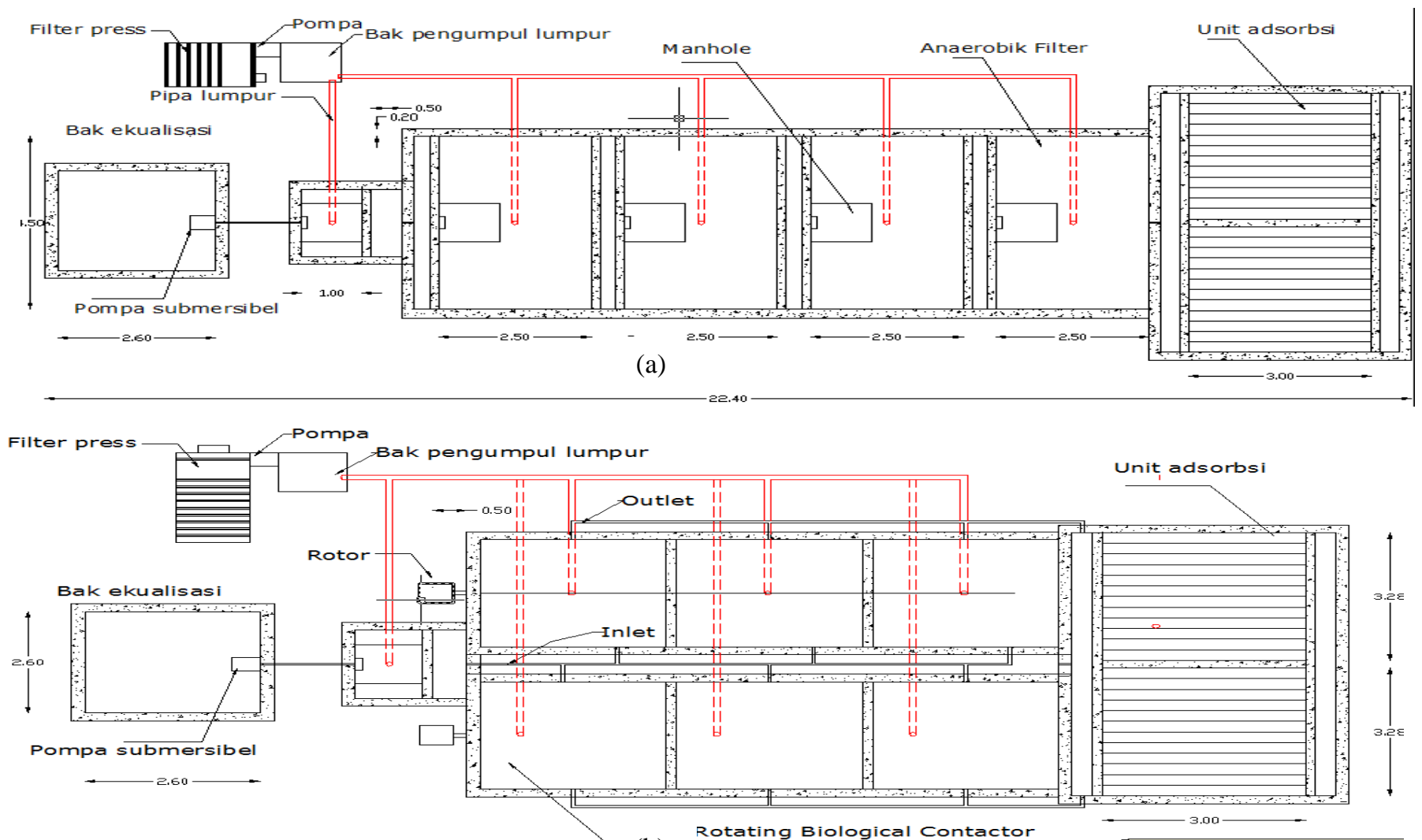

(b)

Gambar 8. Gambar (a) Layout Alternatif 1, (b) ) Layout Alternatif 2. 


\section{H. Perbandingan Pengolahan Alternatif 1 dan 2}

Setelah dilakukan perhitungan DED masing-masing IPAL dan gambar deatail, perhitungan volume pekerjaan ,RAB investasi, operasi dan perawatan dari tiap unit IPAL lalu dilakukan perbandingan kelebihan dan kekurangan dari masing-masing alternative IPAL. Kedua alternatif memiliki pengolahan primer dan lanjutan yang sama, maka yang dibandingkan adalah pengolahan sekundernya saja yaitu anaerobic filter dan RBC.

\section{Alternatif 1 Anaerobic Filter}

Kelebihan:

1) Biaya investasi yang lebih kecil Rp 700.193.694,29.

2) Biaya operasional dan perawatan yang lebih kecil.

3) Tenaga listrik yang digunakan lebih sedikit karena tidak menggunakan rotor untuk suplai oksigen 19,8 kWh.

4) Jumlah lumpur yang dihasilkan lebih sedikit 0,000323 $\mathrm{m} 3 /$ hari.

5) Kebutuhan lahan yang lebih sedikit $45 \mathrm{~m} 2$.

Kekurangan:

1) Waktu tinggal yang lebih lama yaitu 24 jam.

2) Waktu start-up yang lebih lama.

Alternatif 2 RBC

Kelebihan:

1) Waktu tinggal yang lebih singkat yaitu 1,5 jam.

2) Waktu start-up yang lebih singkat.

Kekurangan:

1) Biaya investasi yang lebih besar Rp 777.526.655,53.

2) Biaya operasional dan perawatan yang lebih besar.

3) Tenaga listrik yang digunakan lebih besar karena tidak menggunakan rotor untuk suplai oksigen $20,9 \mathrm{kWh}$.

4) Jumlah lumpur yang dihasilkan lebih banyak $0,91 \mathrm{~m} 3 /$ hari.

5) Kebutuhan lahan yang lebih besar $45,375 \mathrm{~m}^{2}$.

\section{KESIMPULAN}

A. Dari perhitungan DED didapat Dimensi untuk masing masing unit IPAL pada alternatif 1 sebagai berikut Bak ekualisasi (2,6 m x 2,6 x $2 \mathrm{~m})$, Septic tank (1,75 m x 1,5m x 2,5m), Anaerobic Filter 4 kompartemen $(4,5 \mathrm{~m}$ x $2,5 \mathrm{~m} x$ 2,5m), Adsorbsi (3,5 mx 6,75m x 0,55m)

B. Dari perhitungan DED didapat Dimensi untuk masing masing unit IPAL pada alternatif 2 sebagai berikut Bak ekualisasi (2,6 m x 2,6 x $2 \mathrm{~m})$, Septic tank (1,75 m x 1,5m x $2,5 \mathrm{~m})$, RBC 2 shaft $(2,75 \mathrm{~m} \times 2,75 \mathrm{~m} \times 1 \mathrm{~m})$, Adsorbsi $(3,5 \mathrm{mx} 6,75 \mathrm{~m} \times 0,55 \mathrm{~m})$

C. Rencana anggaran biaya investasi, operasi dan perawatan masing alternatif adalah sebagai berikut alternatif 1 biaya investasi sebesar Rp 700.193.694,29, biaya operasi sebesar Rp 50.222.462,40, biaya perawatan sebesar Rp 3.495.000,00. Alternatif 2 biaya investasi sebesar $R p$ 777.526.655,53, biaya operasi sebesar Rp Rp 53.012.599,20 , biaya perawatan sebesar3.495.000,00.

D. Kelebihan Anaerobic filter adalah biaya investasi yang lebih kecil, biaya operasional lebih kecil, tenaga listrik yang digunakan lebih sedikit karena tidak menggunakan rotor untuk suplai oksigen, jumlah lumpur yang dihasilkan lebih sedikit dan luas lahan yang dibutuhkan lebih kecil, sedangkan kekurangannyaadalah waktu tinggal yang lebih lama dan start up yang lama. Kelebihan RBC adalah waktu tinggal yang lebih singkat yaitu 1,5 jam, waktu start-up yang lebih singkat, sedangkan kekurangannya luas lahan lebih besar memerlukan energi listrik, biaya investasi dan operasional yang lebih tinggi.

\section{DAFTAR PUSTAKA}

[1] Sugiharto.1987. Dasar - dasar Pengelolaan Air Limbah, Cetakan Pertama.UI Press.Jakarta.

[2] Hamid, A. 2014. Perbandingan Desain IPAL proses Attached Growth Anaerobic Filter dengan Suspended Growth Anaerobic Baffle Reactor. Tugas Akhir di Jurusan Teknik Lingkungan FTSP-ITS.Surabaya.

[3] Manurung, R dan Hasibuan, R. 2004. Perombakan Zat Warna Azo Reaktif Secara Anaerob - Aerob. Jurusan Teknik Kimia Fakultas Teknik Universitas Sumatera Utara. Medan.

[4] Jannatin, D, R., Razif, M., dan Mursid, M. Uji efisiensi Arang Batok Kelapa untuk Mereduksi Warna dan Permanganate Value dari Limbah Industri Batik. Tugas Akhir di Jurusan Teknik Lingkungan FTSPITS.Surabaya.

[5] Tchobanoglous, G. Burton F.L, Stenset H.D.2003.Waswater Engineering, Treatment and Reuse Fourth Edition. New York:McGrawHill Companies.

[6] Sasse. 1998. DEWATS: Decentralized Wastewater Treatment In Developing Countries. Bremen: BORDA.

[7] Said, N.I. 2005. Aplikasi Bio-Ball untuk Pencucian Jean. Jakarta: BPPT.

[8] Reynolds, T.D., dan Paul A.R.1995. Unit Operations And Processes In Environmental Engineering. PWS Publishing Company.Boston. 